\title{
MAJOR THERMAL-HYDRAULIC PHENOMENA FOUND DURING ATLAS LBLOCA REFLOOD TESTS FOR AN ADVANCED PRESSURIZED WATER REACTOR APR1400
}

\author{
HYUN-SIK PARK*, KI-YONG CHOI, SEOK CHO, KYOUNG-HO KANG, and YEON-SIK KIM \\ Thermal Hydraulics Safety Research Division, Korea Atomic Energy Research Institute \\ 1045 Daedeokdaero, Yuseong, Daejeon, 305-353, Republic of Korea \\ ${ }^{*}$ Corresponding author. E-mail : hspark@kaeri.re.kr
}

Received August 02, 2010

Accepted for Publication February 18, 2011

\begin{abstract}
A set of reflood tests has been performed using ATLAS, which is a thermal-hydraulic integral effect test facility for the pressurized water reactors of APR1400 and OPR1000. Several important phenomena were observed during the ATLAS LBLOCA reflood tests, including core quenching, down-comer boiling, ECC bypass, and steam binding. The present paper discusses those four topics based on the LB-CL-11 test, which is a best-estimate simulation of the LBLOCA reflood phase for APR1400 using ATLAS. Both homogeneous bottom quenching and inhomogeneous top quenching were observed for a uniform radial power profile during the LB-CL-11 test. From the observation of the down-comer boiling phenomena during the LB-CL-11 test, it was found that the measured void fraction in the lower down-comer region was relatively smaller than that estimated from the RELAP5 code, which predicted an unrealistically higher void generation and magnified the downcomer boiling effect for APR1400. The direct ECC bypass was the dominant ECC bypass mechanism throughout the test even though sweep-out occurred during the earlier period. The ECC bypass fractions were between 0.2 and 0.6 during the later test period. The steam binding phenomena was observed, and its effect on the collapsed water levels of the core and down-comer was discussed.
\end{abstract}

KEYWORDS : APR1400, ATLAS, LBLOCA Reflood, ECC Bypass, Down-comer Boiling

\section{INTRODUCTION}

Some advanced pressurized water reactors such as the APR1400 [1] have adopted the new safety feature of a DVI (Direct Vessel Injection) system that supplies the ECC (Emergency Core Coolant) directly into the reactor vessel down-comer. The ECC is supplied from the safety injection system through DVI nozzles that are located in the upper part of the reactor vessel. Since the DVI nozzles are located above the cold legs, the ECC could be discharged directly to a broken cold leg during an LBLOCA (Large Break Loss of Coolant Accident). Even though it is not necessary to assume that one of the four train SIPs (Safety Injection Pumps) spills directly to cold leg break unlike CLI (Cold Leg Injection) system, it is still important to quantify the ECC bypass at the downcomer during the reflood phase. The direct ECC bypass phenomena could limit the ECC penetration into the core through the down-comer and, thus, degrade the core cooling capability during the late reflood phase of the LBLOCA, becoming one of the most important safety issues of an advanced pressurized water reactor, such as the APR1400, which adopts a DVI system to obtain its license from the Korean regulatory organization.

A thermal-hydraulic integral effect test facility, ATLAS (Advanced Thermal-hydraulic Test Loop for Accident Simulation) [2], was constructed at KAERI (Korea Atomic Energy Research Institute) and has been operated to provide reliable data to help validate the safety analysis methodology for APR1400. It is based on the design features of the APR1400, an evolutionary pressurized water reactor developed by the Korean industry. The ATLAS was designed to have the capability of simulating manifold scenarios, including the reflood phase of the LBLOCA, SBLOCA (Small Break LOCA) including a DVI line break, SGTR (Steam Generator Tube Rupture), MSLB (Main Steam Line Break), FLB (Feed Line Break), and mid-loop operation, etc. In particular, the main focus was on the reproduction of the multi-dimensional phenomena related to a DVI as well as the elimination of the scaling distortion of bubble behaviors due to the surface tension effect and the flow regime in the design stage of the reactor vessel and down-comer. In a narrow down-comer gap, the bubble behavior could be distorted due to the surface 
tension effect. The gap width should be wider than the critical gap size to properly simulate the bubble behavior in the down-comer gap, and then the distortion due to the surface tension effect could be eliminated. Accordingly the ATLAS adopted an integrated annulus down-comer, which is the same design feature as the reference plant. Recently, a series of integral effect tests [3] on the LBLOCA reflood phenomena have been carried out in order to investigate the thermal hydraulic phenomena during the reflood phase of the LBLOCA by using ATLAS. The main objective of the test is to understand the major thermal-hydraulic characteristics during the entire reflood period and to obtain reliable data to help resolve the down-comer boiling issues that arise during the APR1400 licensing process.

This paper focuses on the analysis and understanding of the major thermal-hydraulic phenomena of core quenching, down-comer boiling, ECC bypass, and steam binding during the ATLAS reflood test program for APR1400. The analysis was based on the LB-CL-11 test [3], which is one of the integral tests for the reflood phase of an LBLOCA for investigating the thermal-hydraulic characteristics during an entire reflood period to provide reliable data to help validate the LBLOCA analysis methodology for the APR1400. While the LB-CL-09 test [4] is for conservative conditions, the present LB-CL-11 test is for best-estimate conditions. The initial and boundary conditions of the LB-CL-09 and LB-CL-11 tests were determined based on the code analysis on APR1400 for conservative and best-estimate conditions, respectively. The conservative condition is acquired from the EM (Evalulation Model) approach, which assumes an atmospheric containment pressure and a 120\% ANS-73 decay curve, while the best-estimate condition is acquired from the BE (Best-Estimate) approach, which assumes an higher containment pressure of about $0.2 \mathrm{MPa}$ and $102 \%$ ANS-79 decay curve.

\section{DESCRIPTION OF THE ATLAS FACILITY}

ATLAS has the same two-loop features as the APR1400 and is designed according to the well-known scaling methodology suggested by Ishii and Kataoka [5] to simulate the various test scenarios as realistically as possible. The ATLAS is a half-height and 1/288-volume scaled test facility with respect to the APR1400. The main motive for adopting the reduced-height design is to allow for an integrated annular down-comer where the multidimensional phenomena can be important in some accident conditions with DVI operation. According to the scaling law, the reduced height scaling has time-reducing results in the model. For the one-half-height facility, the time for the scaled model is $\sqrt{2}$ times faster than the prototypical time. The friction factors in the scaled model are maintained at the same level as those of the prototype. Major scaling parameters of ATLAS are summarized in Table 1.

A schematic diagram of ATLAS is shown in Fig. 1. The fluid system of ATLAS consists of a primary system, secondary system, safety injection system, break simulating system, containment simulator, and auxiliary systems. The primary system includes a reactor vessel, two hot legs, four cold legs, four intermediate legs, a pressurizer, four reactor coolant pumps, and two steam generators. The secondary system of ATLAS is simplified to be of a circulating loop-type. The steam generated at two steam generators is condensed in a direct condenser tank, and the condensed feed-water is again injected into the steam generators. Most of the safety injection features of the APR1400 and the OPR1000 are incorporated into the safety injection system of ATLAS. It consists of four SITs (Safety Injection Tanks), a high pressure SIP that can simulate safety injection and long-term cooling, a charging pump for charging auxiliary spray, and a shutdown cooling pump and a shutdown heat exchanger for low pressure safety injection, shutdown cooling operation, and recirculation operation. The break simulation system consists of several break simulating lines such as LBLOCA, DVI line break LOCA, SBLOCA, SGTR, MSLB, FLB, etc. Each break simulating line consists of a quick opening valve, a break nozzle, and instruments. It is precisely manufactured to have a scaled break flow rate in the case of LOCA tests. The CS (Containment Simulator) of ATLAS has a function of collecting the break flow and maintaining a specified

Table 1. Major Scaling Parameters of the ATLAS

\begin{tabular}{c|c|c}
\hline Parameters & Scaling law & ATLAS design \\
\hline Height & $l_{0 R}$ & $1 / 2$ \\
\hline Diameter & $d_{0 R}$ & $1 / 12$ \\
\hline Area & $d_{0 R}^{2}\left(=a_{0 R}\right)$ & $1 / 144$ \\
\hline Volume & $l_{0 R} d_{0 R}^{2}$ & $1 / 288$ \\
\hline Core Temperature difference & $\Delta T_{0 R}$ & 1 \\
\hline Velocity & $l_{0 R}^{1 / 2}$ & $1 / \sqrt{2}$ \\
\hline Time & $l_{0 R}^{1 / 2}$ & $1 / \sqrt{2}$ \\
\hline Power/Volume & $l_{0 R}^{-1 / 2}$ & $\sqrt{2}$ \\
\hline Heat flux of a heater rod & $l_{0 R}^{-1 / 2}$ & $\sqrt{2}$ \\
\hline Heat flux through RPV wall & $d_{0 R} \cdot l_{0 R}^{-1 / 2}$ & $1 / 8.49$ (ideal) \\
\hline Core power & $l_{0 R}^{1 / 2} d_{0 R}^{2}\left(=Q_{0 R}\right)$ & $1 / 203.6$ \\
\hline Flow rate & $l_{0 R}^{1 / 2} d_{0 R}^{2}$ & $1 / 203.6$ \\
\hline Pressure drop & $l_{0 R}$ & $1 / 2$ \\
\hline
\end{tabular}


back-pressure in order to simulate containment pressure. The CS is mainly composed of two separating vessels, five measuring vessels to measure the accumulated water mass, a flow meter to measure the steam flow rate, and a pressure control valve to control the containment pressure. In addition, ATLAS has some auxiliary systems such as a makeup water system, component cooling water system, nitrogen/air/steam supply system, vacuum system, and heat tracing system.

A total of 396 electrical heaters and unheated rods are used to simulate the fuel rods. There are 390 electric heaters which are divided concentrically into three groups (Group-1, Group-2, and Group-3). Group-1, -2, and -3 heaters are located in the inner, middle, and outer regions of the heater bundle, respectively, and they have 102, 138, and 150 heaters, respectively. In addition, the core heater bundle has six unheated rods. The axial power profile of each heater rod is the 'chopped cosine' power shape. The simulated fuel assembly type is $16 \times 16$, and the outer diameter of heater rod is $9.5 \mathrm{~mm}$, which is the same as the prototypical rod diameter of APR1400. A total of 264 and 42 thermocouples were installed in the core heater bundle to measure the heater surface and fluid temperatures, respectively, which were inserted into grooves on the heater rod surface.
The detailed ATLAS design and a description of ATLAS development program can be found in the literature [6-7], as well as a detailed description of the signal processing system and control system of ATLAS [8]. In the ATLAS test facility, a total of 1,236 instrumentations are installed for the measurement of thermal-hydraulic parameters in the components.

\section{EXPERIMENTAL CONDITION AND PROCEDURE}

The ATLAS LBLOCA reflood tests [3] include both Phase- 1 and Phase- 2 tests. Phase- 1 tests are parametric effect tests for down-comer boiling phenomena in a reactor pressure vessel during the late reflood period of LBLOCA, and Phase- 2 tests are integral effect tests for the thermalhydraulic phenomena in the core and down-comer during the entire reflood period of LBLOCA to provide important thermal-hydraulic parameters such as the peak cladding temperature and so on for an evaluation of the safety analysis code and the corresponding licensing methodology. The overall thermal-hydraulic trends, such as level variation and the core quench phenomena in the RPV (Reactor Pressure Vessel) are similar, but the specific values of the maximum rod surface temperature and

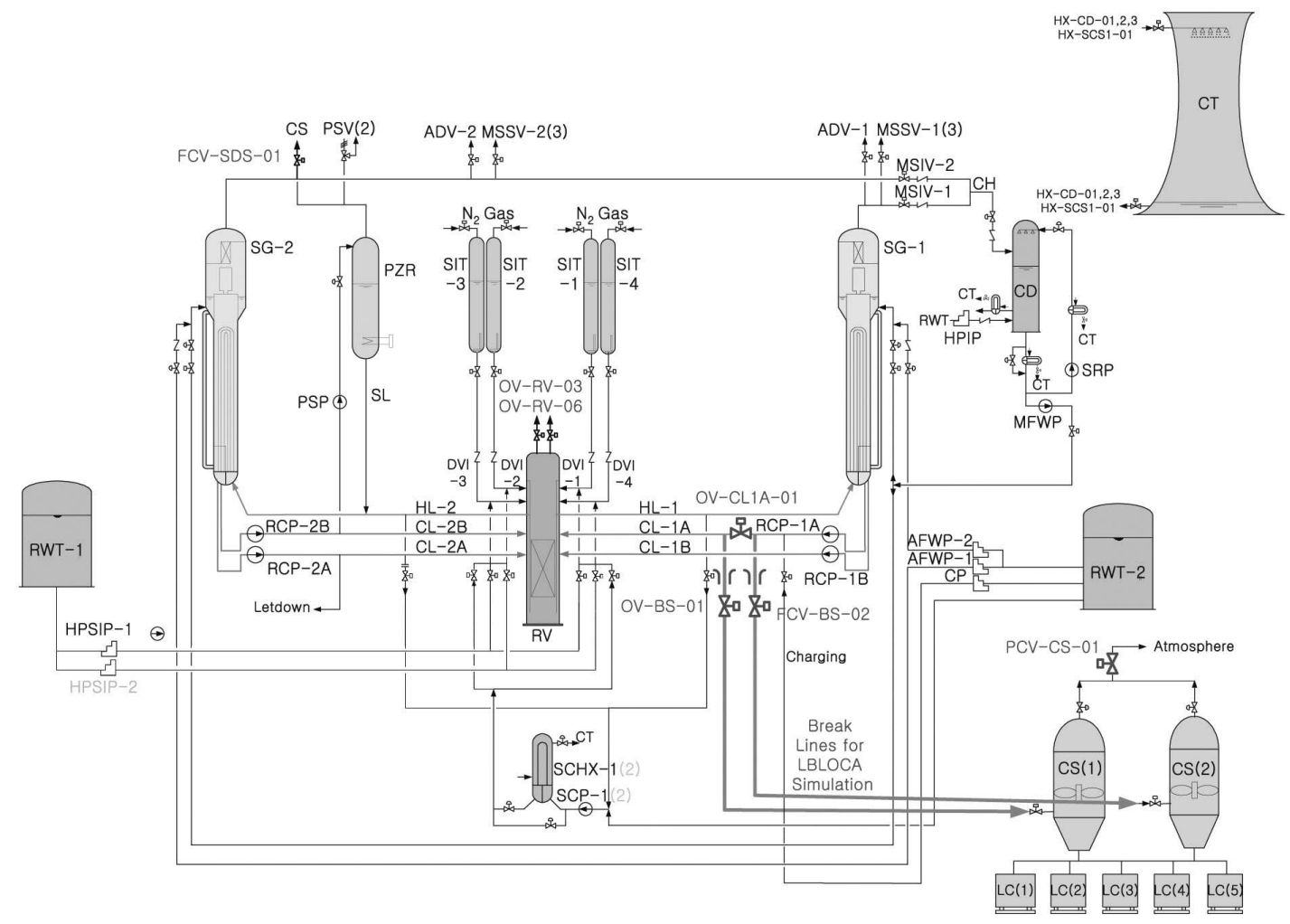

Fig. 1. Schematic Diagram of the Overall ATLAS for the LBLOCA Simulation 
rewetting time are quite different between the three Phase- 2 tests. Among them, the present LB-CL-11 test was selected as an integral effect test for the reflood phase of LBLOCA, which is a best-estimate simulation of the LBLOCA reflood period. The core heater power is lower and the system pressure is higher during LB-CL11 (a best-estimate test) than those during LB-CL-09 (a conservative test), which induces a higher maximum heater rod surface temperature and a longer rewetting time.

The initial and boundary conditions of LB-CL-11 were obtained by applying scaling ratios in Table 1 to the MARS simulation results. [9] Table 2 shows a summary of the initial and boundary conditions. The ECC flow rate from the SIT and the decay heat were simulated from the start of the reflood period. The ECC water flow rate from the high pressure SIP was $0.32 \mathrm{~kg} / \mathrm{s}$. In ATLAS, the ECC water was supplied from the RWT, and the temperature of $50^{\circ} \mathrm{C}$ was kept the same as that of the APR1400. At the start of a reflood, the system pressure at the downcomer was around $0.32 \mathrm{MPa}$, but the containment simulator pressure was fixed at about $0.2 \mathrm{MPa}$ during the test to simulate a best-estimate condition. The core decay heat was 169.1 MW at the reflood start, and, thus, the initial heater power should be fixed to a scaled-down power of $830.3 \mathrm{~kW}$, and 1.02 times that of the ANS-79 decay curve should be used thereafter. The same power per rod and linear power density should be given to the heaters, and

Table 2. Summary of the Initial and Boundary Conditions for LB-CL-11

\begin{tabular}{|c|c|c|c|}
\hline Variables & Target Value & Test Results & Description \\
\hline $\begin{array}{l}\text { Power } \\
(\mathrm{kW})\end{array}$ & 830.3 & 830.3 & $\begin{array}{l}1.02 * \text { ANS-79 Curve } \\
\text { (after reflood) }\end{array}$ \\
\hline \multirow{4}{*}{$\begin{array}{l}\text { Pressure } \\
(\mathrm{MPa})\end{array}$} & 0.25 & $0.15 \sim 0.25$ & RPV down-comer \\
\hline & 5.0 & $4.4 \sim 5.0$ & SG steam dome \\
\hline & 0.20 & $0.15 \sim 0.21$ & CS PCV downstream \\
\hline & $4.3 / 2.3$ & $4.3 / 2.2 \sim 2.5$ & SIT (initial/reflood) \\
\hline \multirow{3}{*}{$\begin{array}{c}\text { ECC Flowrate } \\
(\mathrm{kg} / \mathrm{s})\end{array}$} & below 3.93 & $2.41 \sim 3.53$ & SIT-High Flow \\
\hline & 0.98 & $0.79 \sim 1.13$ & SIT-Low Flow \\
\hline & 0.32 & $0.30 / 0.31$ & SIP-1 \& -3 \\
\hline \multirow{3}{*}{$\begin{array}{l}\text { Temperature } \\
\left({ }^{\circ} \mathrm{C}\right)\end{array}$} & 205 & 207 & RPV wall \\
\hline & $50 / 50$ & $51 / 50$ & SIT / RWT-1 \\
\hline & 456 & 459 & $\begin{array}{l}\text { Maximum heater rod } \\
\text { surface temperature }\end{array}$ \\
\hline \multirow{2}{*}{$\begin{array}{l}\text { Level } \\
(\mathrm{m}, \%)\end{array}$} & 0.534 & 0.41 & RPV lower plenum \\
\hline & $94 / 50$ & $94 / 55$ & SIT / RWT-1 \\
\hline
\end{tabular}

their initial values were $2.129 \mathrm{~kW}$ and $1.118 \mathrm{~kW} / \mathrm{m}$, respectively. From the scaling criteria for the total energy of the down-comer heat structure, the initial outer wall temperature was determined to be $205^{\circ} \mathrm{C}$. During the LBCL-11 test, the initial wall temperatures of the downcomer at the reflood start time were around $187^{\circ} \mathrm{C}$ and $207^{\circ} \mathrm{C}$ for the inner and outer walls, respectively. In the ATLAS, four bypass flow control valves were installed at the reactor pressure vessel to simulate the downcomer-upper head and downcomer-hot leg bypass flows. The bypass flow rates were controlled to provide the scaled values through the bypass flow lines based on the performance tests for four bypass valves connected to the down-comer. [10]

Table 3 shows a summary of the major events for the LB-CL-11 test. During the heat-up process of the LBCL-11 test, the primary system was heated with core heaters to its specified wall temperature of $270^{\circ} \mathrm{C}$ and pressurized to a specific pressure of $8.1 \mathrm{MPa}$, and steady state conditions were maintained to stabilize the system behavior of the ATLAS facility. The water inventory in the secondary side of each steam generator was also heated by the heat transferred through the steam generator U-tube and pressurized to a specified temperature of $265^{\circ} \mathrm{C}$ and a pressure of 5.4 $\mathrm{MPa}$. Subsequent to the heat-up process, an initialization process was carried out to obtain the required initial and boundary conditions for the LBLOCA reflood test throughout the primary and secondary systems.

\section{MAJOR THERMAL-HYDRAULIC PHENOMENA}

Several important phenomena were observed during the ATLAS LBLOCA reflood tests. They include the phenomena of core quenching, down-comer boiling, ECC bypass, and steam binding. Those four topics will be discussed based on the LB-CL-11 test, which is a best-estimate simulation of the LBLOCA reflood phase for APR1400 using ATLAS.

\subsection{Core Quenching Behavior}

During the reflood process, the heater rod is quenched not only by the ECC injected from the core bottom, but also by the accumulated water falling from the upper plenum to the core top, which are named 'bottom quenching' and 'top quenching', respectively. While the bottom quenching progresses uniformly in a radial direction, the top quenching shows radial in-homogeneity. Accumulation of the water at the upper plenum and core top, as shown in Fig. 2, is mainly due to a de-entrainment of the entrained droplets by high-velocity steam in a form of clusters of liquid droplets. The liquid is entrained from just downstream of the quench front, and it is de-entrained by a decreasing steam velocity due to an enlarged flow area at the core exit. As the wall temperatures of heat structure at the core exit and in the upper plenum remained higher than the saturated water temperature at the core exit, it is considered that the 

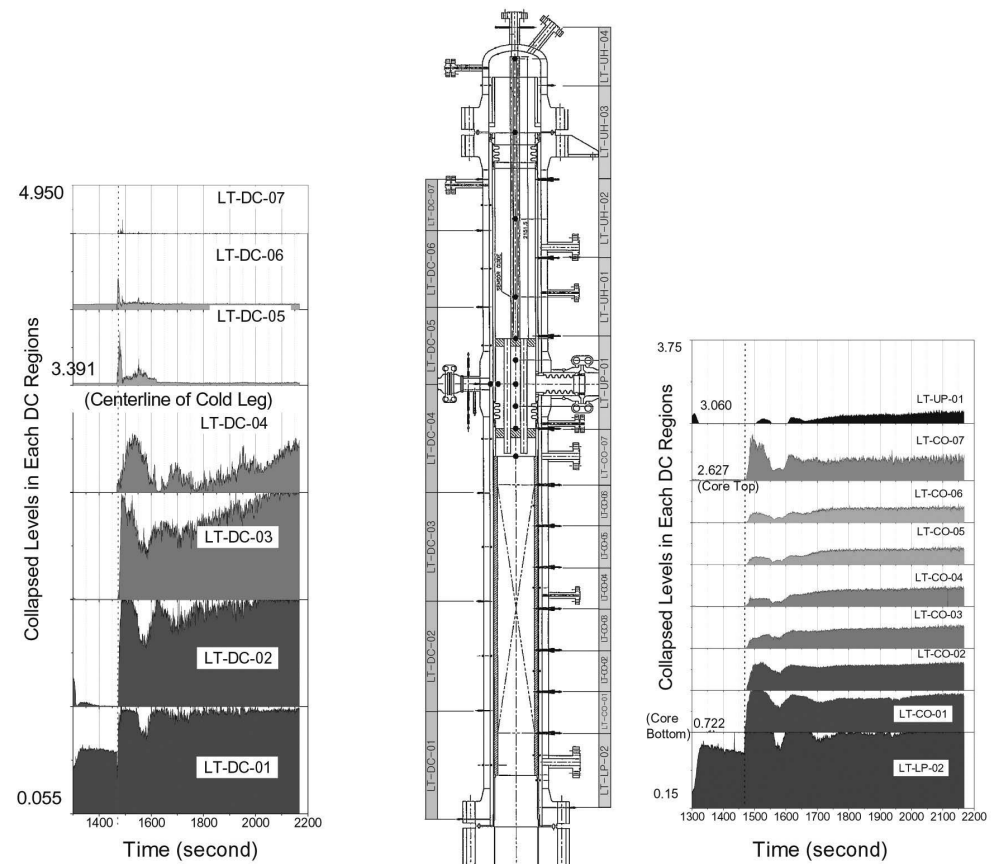

Fig. 2. Sectional Water Level Variations in the Down-comer and Core Regions During LB-CL-11

Table 3. Summary of the Major Events for LB-CL-11

\begin{tabular}{|c|c|c|c|}
\hline Events & Time (DAS) (s) & Time (from Reflood) (s) & Description \\
\hline Test Start & 0 & - & Data Recording Start \\
\hline Heating End & 643 & - & Core/RCP Trip, SS Isolation, Heater Power Off \\
\hline Vent & 739 & - & 3 Vent Valves Open (RPV Top, 2 EA, PZR SDS line, 1 EA) \\
\hline \multirow{3}{*}{ Drain } & 1076 & - & P<3.0 MPa: FCV-BS-02 20\% Open \\
\hline & 1129 & - & $\mathrm{P}<2.5 \mathrm{MPa}:$ FCV-BS-02 40\% Open \\
\hline & 1169 & - & $\mathrm{P}<1.5 \mathrm{MPa}:$ FCV-BS-02 100\% Open \\
\hline BS Open & 1230 & - & $\begin{array}{l}\text { P<0.5MPa: OV-BS-01 Open; } \\
\text { OV-CL1A-01 Close; Tracing Off; Vent Valves Close }\end{array}$ \\
\hline IL Drain & 1240 & - & Intermediate lines are emptied. \\
\hline Power Restart & 1399 & -68 & $\begin{array}{l}\text { After Achievement of ICs; } \\
20 \text { s linear increase }\end{array}$ \\
\hline \multirow{3}{*}{ SIT Injection } & 1465 & -2 & Max. $\mathrm{T}>450^{\circ} \mathrm{C}$ (target: $456^{\circ} \mathrm{C}$ ) \\
\hline & 1492 & 25 & SIT-High Flow (94\% 72\%) \\
\hline & 1621 & 154 & SIT-Low Flow $(72 \% \sim 47 \%)$ \\
\hline Reflood Start & 1467 & 0 & $\begin{array}{l}2.0 \mathrm{~s} \text { after SIT Injection; } \\
1.02 * \text { ANS-79 Curve }\end{array}$ \\
\hline SIP Injection & 1482 & 15 & $12.7 \mathrm{~s}$ after Reflood Start \\
\hline Test End & 2167.5 & 700.5 & TW-DC-AVG $<131^{\circ} \mathrm{C} ;$ DAS Stop \\
\hline
\end{tabular}


water accumulation at the core top and in the upper plenum is not caused by steam condensation. Previously similar results were already reported during the experiments of CCTF and SCTF [11], and the general behavior of core quenching in ATLAS was analyzed for the LB-CL-09 test [12].

Figure 3 presents the axial surface temperature distributions of three heater groups during the LB-CL-11 test. A top quenching phenomena was observed both in heater groups 1,2 , and 3 , which were located in the center (Group-1), middle (Group-2), and outer (Group-3) regions of the core, respectively. A top flooding was more strongly observed in Group-1 and Group-2 heaters than in Group3 heaters during the LB-CL-11 tests. The experimental results showed that CCFL (Counter-Current Flow Limitation) did not reach flooding at the core exit and some coolant dropped down into the core simulator. Concerning the radial inhomogeneous top quenching, it was considered that the coolant dropped down more easily in the center and middle regions than in the outer region in the ATLAS facility. During the LB-CL-11 test, the same power per rod was given to the heaters, and its initial value was $2.129 \mathrm{~kW}$. Similar top quenching phenomena was observed for the LB-CL-09 tests, which also have a uniform radial power profile [4]. However, the top quenching phenomena was more quickly finished in Group-3 than in Group-1 and Group-2 during the LBCL-14 test because the radial power distribution of the APR1400 is simulated and the initial powers per rod for heater groups 1,2 , and 3 are $2.438,2.434$, and $1.638 \mathrm{~kW}$, respectively [13]. This difference of top flooding behavior might be caused by the flow and heat transfer characteristics in the complicated geometry between the upper plenum and core top, which should be analyzed three-dimensionally with thermocouples installed on the heater surface and in the fluid.

Figure 4 shows the behavior of quench temperatures and quench times along the axial elevation of the active core during LB-CL-11. The quenching of the heater cladding was progressed both from the lower and upper parts of the rods. However, early quenching phenomena could be observed at the upper third part of the active core region, especially at the heights of $1.517,1.645$, and $1.819 \mathrm{~m}$ above the active core bottom. In the LB-CL-11 test, the quench times of Group-1 and Group-2 were shorter than those of Group-3, as is also shown in Fig. 3. During the LB-CL-11 test the maximum rod surface temperature was $558 \mathrm{oC}$. The whole quenching process
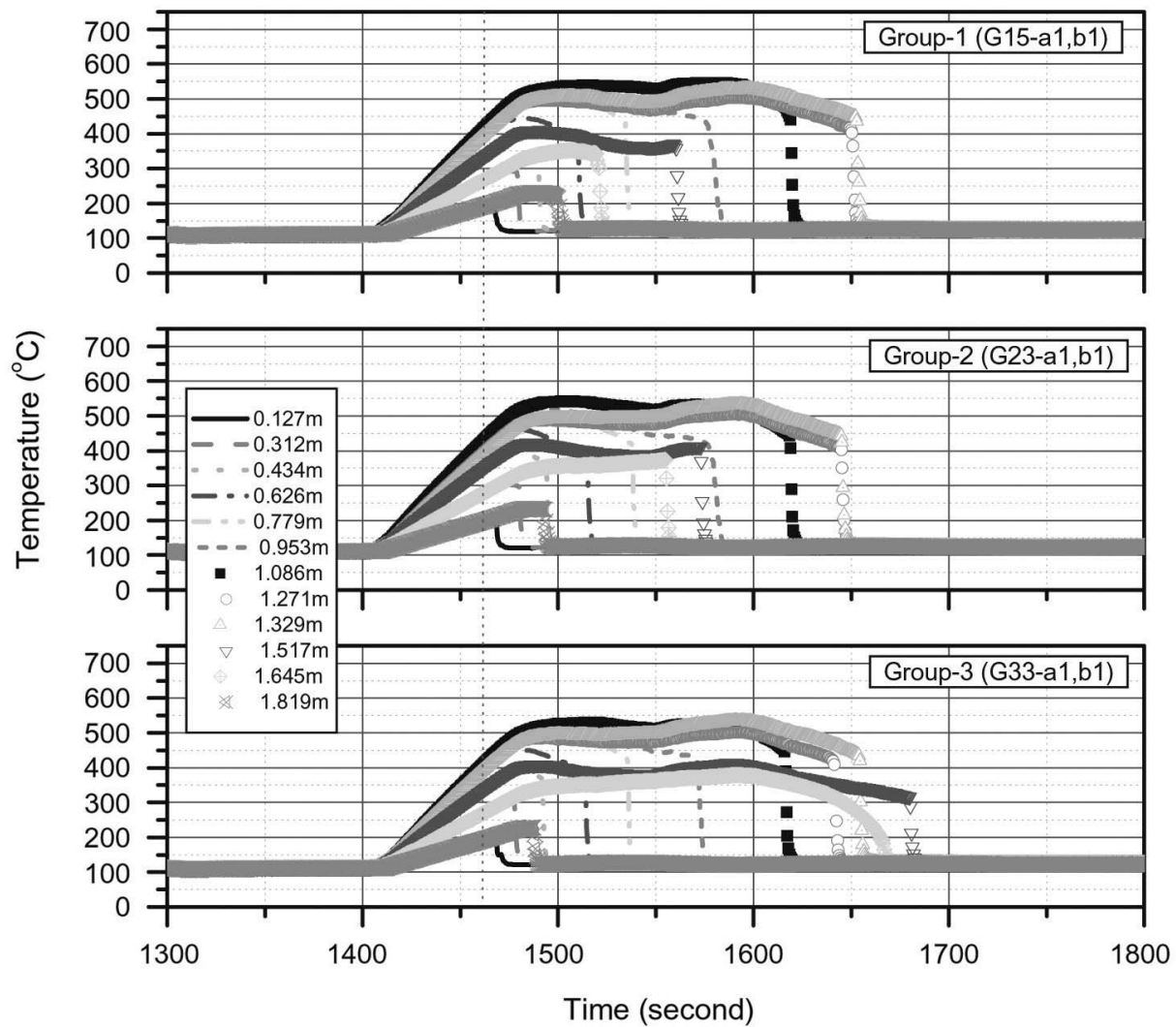

Fig. 3. Axial Surface Temperature Distributions of Three Core Heater Rods During LB-CL-11 (Group-1, 2, \& 3) 
was finished in $218 \mathrm{~s}$ after the initiation of the reflood and the averaged rewetting velocity, which was estimated by using the height information of each thermocouple, and the evaluated quench time was about $0.87 \mathrm{~cm} / \mathrm{s}$. As the ATLAS is a half-height facility and its scale ratio of velocity is $1 / \sqrt{2}$, as shown in Table 1 , the corresponding rewetting velocity is expected to be $1.23 \mathrm{~cm} / \mathrm{s}$ in the APR1400.

\subsection{Down-comer Boiling}

Hydraulic phenomena in the down-comer of a conventional pressurized water reactor have an important effect on the transient evaluations of a postulated LBLOCA. Following an LBLOCA, the stored energy in the vessel metal mass might cause down-comer boiling after the accumulator injection is terminated [14]. Voiding in the down-comer could reduce its hydraulic head significantly, and then it could reduce a subcooling of the coolant entering the core and increase the possibility of the loss of the coolant mass out of the break as well. The main concern is that the down-comer boiling phenomena might reduce the flooding rate and consequently increase the peak cladding temperature. The down-comer boiling became a licensing issue in Korea, and it also became a safety issue with the NRC (Nuclear Regulatory Commission) staff in 2001 [15]. This down-comer boiling phenomena was predicted in the safety analysis using RELAP5/MOD3.2
[16], but it was not observed in the calculation results of the other best-estimate safety analysis codes such as the TRAC-M/F code. Several separate effect tests were performed by using the DOBO facility [14, 17] to show that the reduction of the hydraulic head due to down-comer boiling was not so significant in their test conditions for the reflood phase of the APR1400 LBLOCA scenario. The ATLAS reflood test results could be analyzed on the issue of down-comer boiling, and they were compared with those from separate effect tests and from code simulation. Previously, the down-comer boiling phenomenon was investigated based on the LB-CL-05 test, which is one of parametric effect tests for down-comer boiling in the late reflood phase of an LBLOCA [18]. In the present paper, down-comer boiling will be discussed based on the LBCL-11 test, which is one of the integral effect tests for the entire reflood period of an LBLOCA in a best-estimate condition. Their test conditions were mainly different in that the initial water levels in the down-comer were around the cold leg bottom line and just below the active core region for the LB-CL-05 and LB-CL-11 tests, respectively.

The initial and boundary conditions of the downcomer wall are determined by scaling analysis [19]. In the ATLAS, the power should be scaled down in order to preserve the same thermal-hydraulic phenomena. A lumped heat transfer equation for nucleate boiling, which is expected to be a dominant heat transfer regime on the
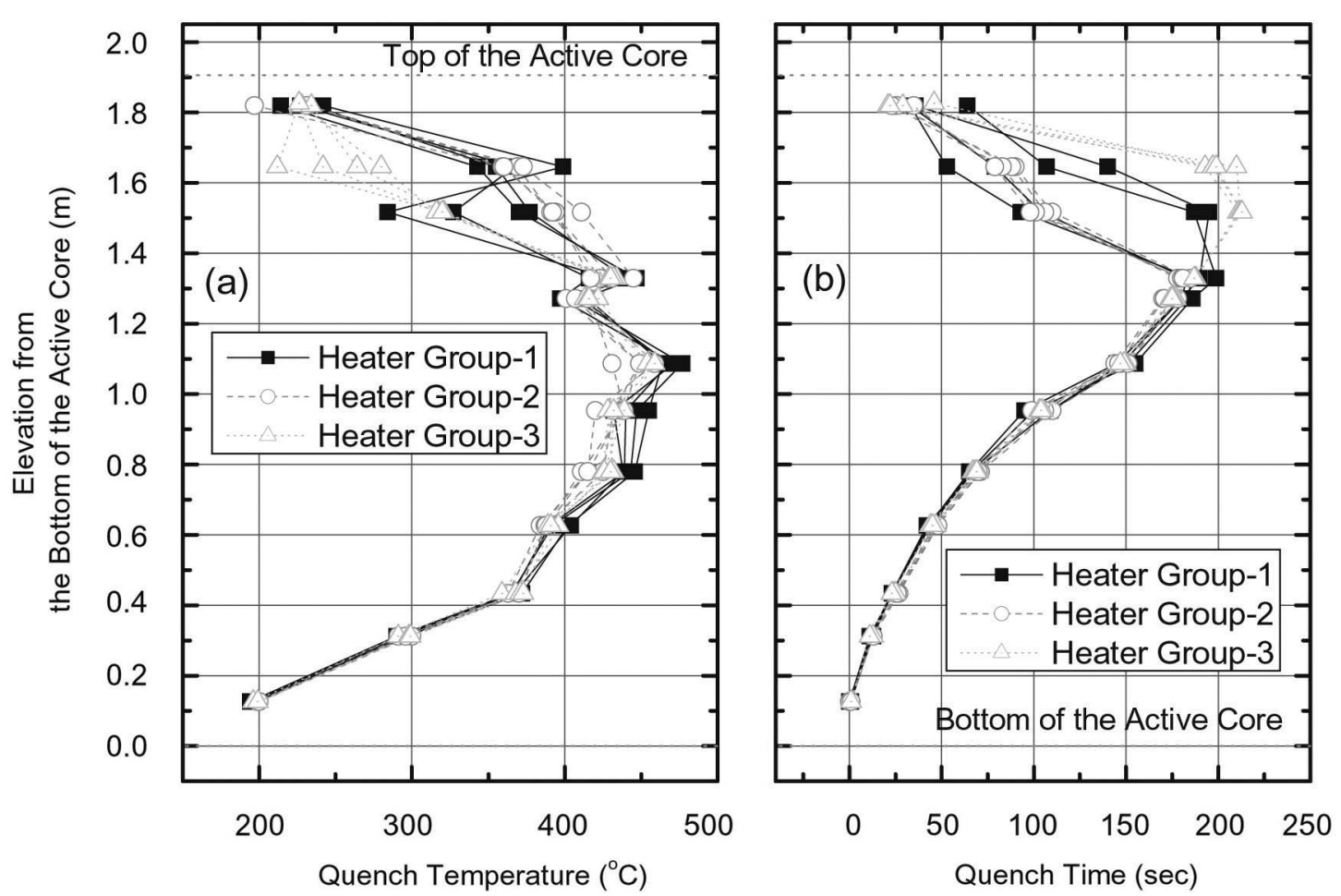

Fig. 4. Behavior of Quench Temperatures and Quench times along the Axial Elevation of the Active Core During LB-CL-11 
down-comer wall, can be expressed as

$$
Q=h \cdot A \cdot\left(T_{w}-T_{b}\right)^{m}
$$

where $Q, h, A, T_{w}$, and $T_{b}$ are the heat transfer rate, the heat transfer coefficient, the heat transfer area, the wall temperature, and the bulk temperature, respectively. Various correlations on nucleate boiling correlations were gathered and compared. A typical correlation was developed by Stephan and Abdelsalam [20], and the exponent $m$ has values ranging from 2.0 to 4.0 depending on the selected nucleate boiling correlations.

A scaling ratio of the heat transferred from an annular down-comer wall to the bulk fluid can be written as

$$
\begin{aligned}
Q_{0 R}= & \frac{Q_{m}}{Q_{p}}=\frac{h_{m}}{h_{p}} \cdot \frac{A_{m}}{A_{p}} \cdot\left\{\frac{\left(T_{w}-T_{b}\right)_{m}}{\left(T_{w}-T_{b}\right)_{p}}\right\}^{m}, \\
& \approx 1 \cdot\left(a_{0 R}^{1 / 2} \cdot l_{0 R}\right) \cdot\left\{\frac{\left(T_{w}-T_{b}\right)_{m}}{\left(T_{w}-T_{b}\right)_{p}}\right\}^{m},
\end{aligned}
$$

where $Q_{0 R}, a_{0 R}$, and $l_{0 R}$, are the scaling ratios of a heat transfer rate, an area, and a length, respectively, and the subscripts of $0, R, m$, and $p$ mean the reference, the ratio, the model, and the prototype, respectively. As $Q_{0 R}$ is equal to $a_{0 R} \cdot l_{0 R}^{1 / 2}$ as shown in Table 1 , the temperature difference ratio is, thus, determined by

$$
\frac{\left(T_{w}-T_{b}\right)_{m}}{\left(T_{w}-T_{b}\right)_{p}}=\left(a_{0 R}^{1 / 2} \cdot l_{0 R}^{-1 / 2}\right)^{1 / m},
$$

and it has a value ranging from 0.35 to 0.59 depending on the selected nucleate boiling correlations. The area scaling ratio of $1 / 128.7$ is used instead of an ideal value of $1 / 144$ to consider the wider flow area due to the enlarged downcomer gap in the ATLAS facility. The final temperature difference ratio of 0.50 is selected as a reference value, where the exponent has a value of 3.0. According to the calculation results by the MARS code, the outer downcomer wall temperature of the APR1400 is maintained at about $290^{\circ} \mathrm{C}$ during the reflood phase. Therefore, the initial outer down-comer wall temperature for the present test was determined to be $205^{\circ} \mathrm{C}$.

The down-comer wall temperatures were measured at 7 locations, the elevations of which are $0.472,1.306,2.140$, 2.974, 3.686, 4.276, and $4.761 \mathrm{~m}$ from the RPV bottom. The bulk fluid temperature was also measured at the same elevation to the wall temperature. The heat flux from the down-comer wall was calculated from the measured temperature difference between the inner and outer walls of the down-comer by assuming a quasi-steady state condition.

$$
q_{R}^{\prime \prime}=-k \cdot \frac{\Delta T}{\Delta x}=-k \cdot \frac{T_{w o}-T_{w i}}{x_{o}-x_{i}}
$$

The maximum heat flux is $23.4 \mathrm{~kW} / \mathrm{m}^{2}$ at $1,483 \mathrm{~s}$, which is $16 \mathrm{~s}$ after the reflood start. The heat flux calculated from the difference between the inner and outer wall temperatures could be scaled-up to the prototypical APR1400 condition by considering the heat flux scaling ratio of $d_{R} \cdot l_{R}^{-1 / 2}$ The maximum heat flux of $23.4 \mathrm{~kW} / \mathrm{m}^{2}$ acquired during the ATLAS test corresponds to $199 \mathrm{~kW} / \mathrm{m}^{2}$ in the LBLOCA analysis of the APR1400. To compare the code calculation results with the experimental data, the maximum heat flux was matched at 1,483 s between the ATLAS data and the APR1400 calculation, and thereafter the code calculation results could be compared each other. Therefore, the present thermal hydraulic conditions in the down-comer could be compared with those in the APR1400 after 1,483 s.

Figure 5 shows a comparison of the heat flux between ATLAS and the APR1400 by synchronizing the progress time. The measured heat flux is a little higher than that in APR1400, but it is comparable to that of the APR1400. When the outer wall temperature of the down-comer is compared between the APR1400 simulation and the ATLAS data, the simulated wall temperature of the APR 1400 maintains a constant value, but the measured wall temperature of the ATLAS decreases more rapidly than that of the APR1400. This is due to a higher heat loss to the environment in the ATLAS test than the APR1400 design. During the APR1400 simulation, the outer surface of the RPV wall is set to be in an insulated condition.

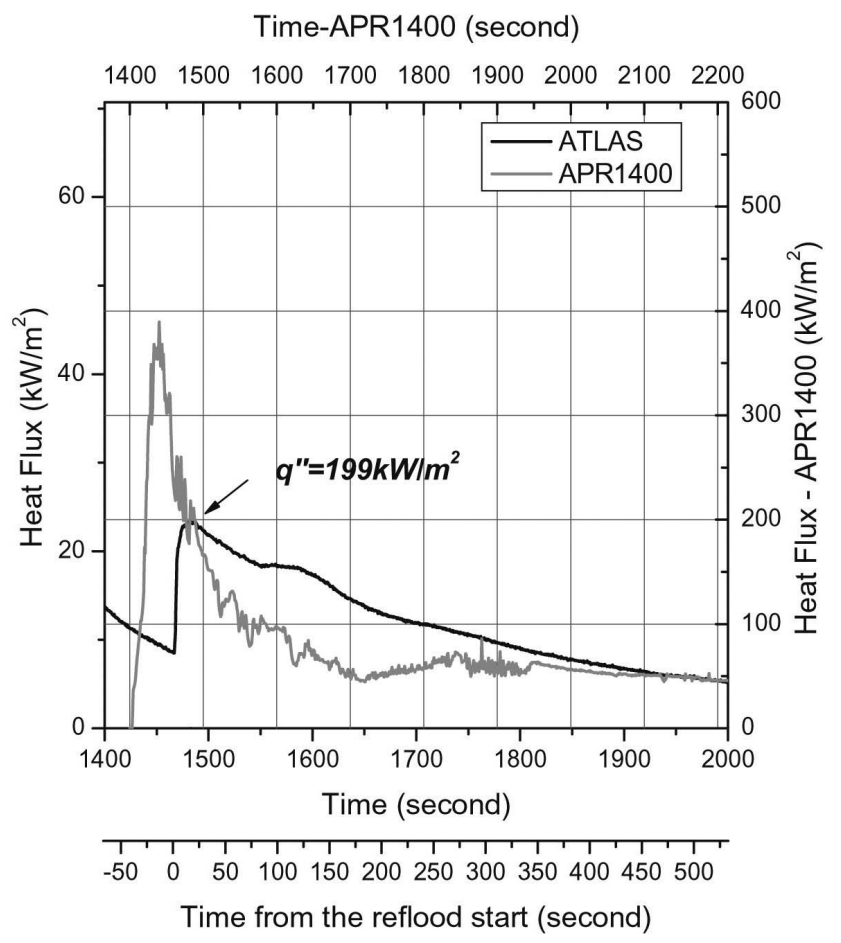

Fig. 5. Comparison of Measured Heat Flux with the Reference Heat Flux 
Figure 6 shows the total collapsed water level variations of the core and down-comer of the reactor pressure vessel of ATLAS during LB-CL-11. Their sectional collapsed water level variations were already shown in Fig. 2. As the ECC injected from the SIT has a relatively high flow rate in the early stage of the reflood, the water levels, both in the down-comer and the core, increased abruptly. When the mixture level reaches the level within the critical void height, which will be discussed in the next sub-section, a sweep-out occurs. As a sweep-out occurs, the break flow rate increases and the ECC bypass fraction increases very rapidly. When the fluid temperature in the down-comer reaches a saturated condition due to the heat from the down-comer wall, the collapsed water level decreases drastically in around 1,550 s due to the significant sweep-out and increased direct ECC bypass. As shown in Fig. 2, the mixture water level is detected around cold leg elevation (LT-DC-05) until 1,620 s, and, thus, it was considered that the sweep-out occurs due to the higher mixture level. The effect of the sweep-out could be excluded after that time because the down-comer water level is sufficiently lower than that of the cold leg bottom (3.347 $\mathrm{m}$ from RPV bottom). As the vessel wall was cooled down steadily and the core was fully quenched in around $1,650 \mathrm{~s}$, the sub-sectional collapsed levels increased steadily with some fluctuation after that. Although the test was not directly simulated by the RELAP5 code, the measured void fraction in the lower down-comer region was relatively smaller than that estimated from the RELAP5

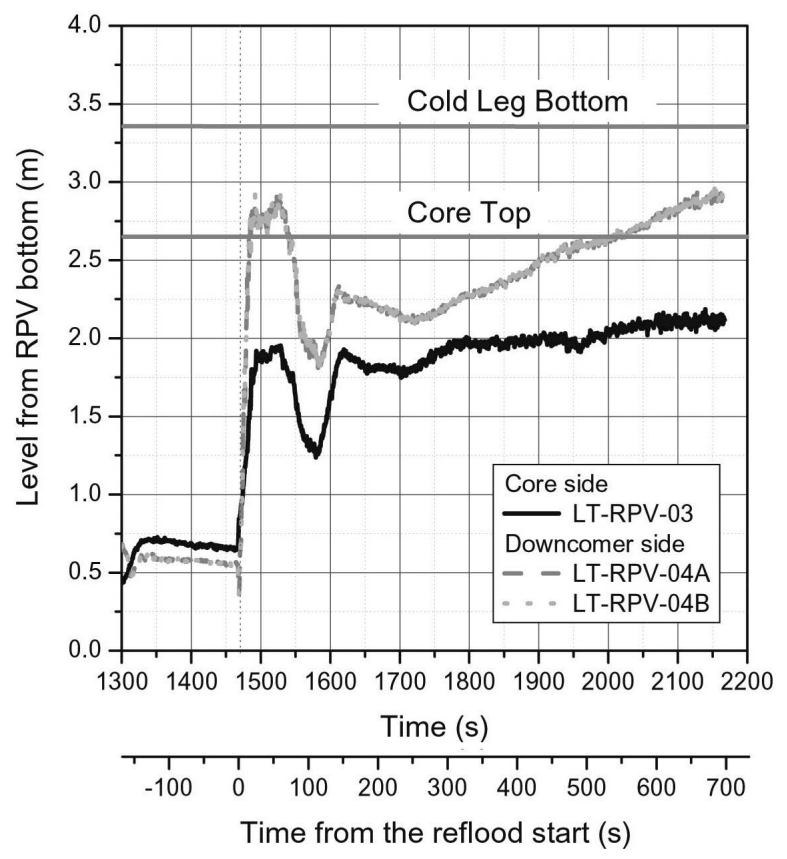

Fig. 6. Total Collapsed Water Level Variations of the Reactor Pressure Vessel During LB-CL-11 code, which predicted an unrealistically higher void generation and magnified the down-comer boiling effect for APR1400 [16].

\subsection{ECC Bypass}

The APR1400 adopts a new safety feature of a DVI system that supplies the ECC directly into the reactor vessel down-comer. The ECC water is supplied through four independent trains of the safety injection system. Even though it is not necessary to assume one of the four train SIPs spill directly to the cold leg break, unlike the CLI system, it is still important to quantify the ECC bypass at the upper down-comer along the lateral direction to the break during the reflood phase [21]. Figure 7 shows the ECC bypass mechanism in the DVI system during the reflood phase. It is generally known that there are two ECC bypass mechanisms of a sweepout and a direct ECC bypass. A sweep-out is caused by the steam injected from the intact cold legs, which interacts with the coolant in the down-comer and induces the coolant to be discharged to the broken cold leg. From the UPTF test results [22], it could be found that a direct ECC bypass is the major bypass mechanism of the DVI system. The ECC bypass has been identified as playing an important role in a depletion of the coolant inventory in the reflood phase of an LBLOCA.

During the LBLOCA reflood test, the ECC bypass fraction is evaluated from the measured break flow rate data, which is measured separately for a steam and water

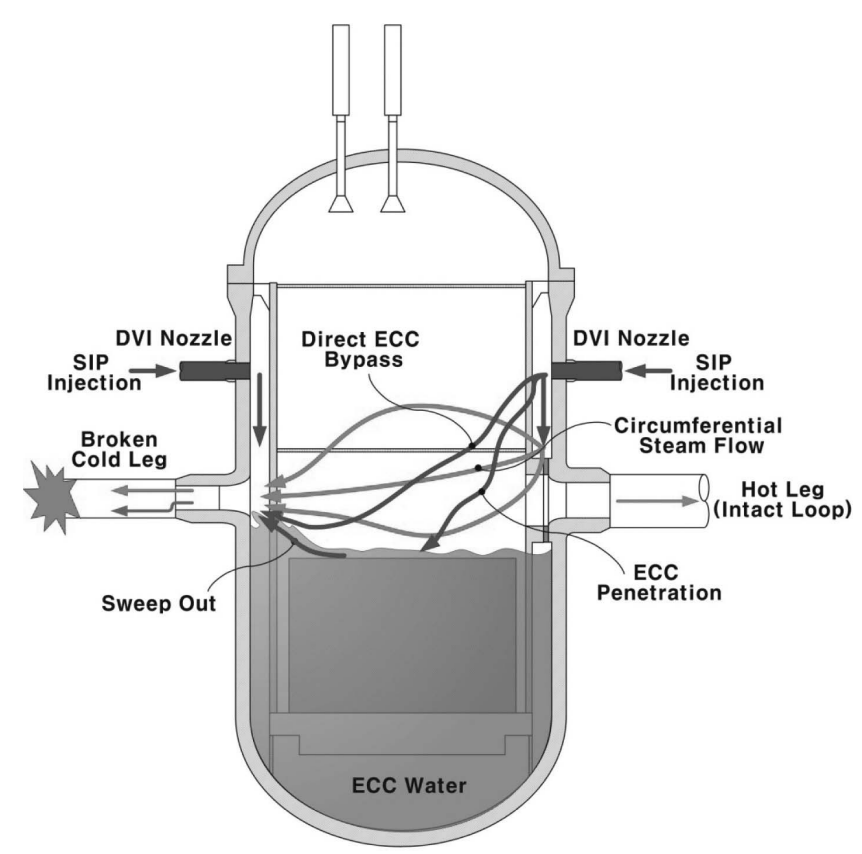

Fig. 7. ECC Bypass Mechanism in the DVI System During the Reflood Phase 
mixture [23]. The ECC bypass fraction is defined as follows:

$$
R_{E C C, \text { bypass }}=\frac{W_{E C C, \text { bypass }}}{W_{E C C}}=\frac{W_{\text {Break,water }}}{W_{E C C}},
$$

where $W_{E C C, \text { bypass }}, W_{\text {break, water }}$, and $W_{E C C}$ are the bypassed ECC flow rate, the water component of a break flow rate, and the injected ECC flow rate. The bypassed ECC flow rate is calculated from the water component of a break flow rate. Before every break, the CS was pre-heated up to $100^{\circ} \mathrm{C}$ by using the steam discharged from the SST (Steam Supply Tank), which could be pressured to $1.0 \mathrm{MPa}$ and heated up to $180^{\circ} \mathrm{C}$. It is considered that the amount of steam condensation is negligibly small through the break simulation line and in the CS. It should also be noted that Equation (5) includes both direct ECC bypass and sweep-out. In the break simulation system of the ATLAS both direct ECC bypass and sweep-out are measured together, and there is no measure to differentiate them. Initially both direct ECC bypass and sweep-out occur together until the down-comer level decreases below the cold leg. When the level in the down-comer is low enough below the critical void height, as described in Equation (6), the sweep-out does not occur anymore, and then only the direct ECC bypass occurs. As shown in Fig. 2, a little liquid level was measured in LT-DC-05, which is located just above the centerline of the cold leg, instantly after the incipience of the ECC injection $(1,482$ $\mathrm{s}$ ), and it continued until the significant decrease of the sub-sectional down-comer level of LT-DC-04 (1,621 s). It could be presumed that the sweep-out occur between $1,482 \mathrm{~s}$ and 1,621 s during the LB-CL-11 test. Therefore, in terms of direct ECC bypass, Equation (5) is valid after $1,621 \mathrm{~s}$.

As for the onset of an entrainment that induces the sweep-out phenomena, a simple calculation was performed using Cho's correlation [24]. Critical void height $\left(h_{b}\right)$, below which a sweep-out is started by the steam injected from the intact cold legs, can be calculated from the following correlation:

$$
\operatorname{Fr}_{g}\left[\frac{\rho_{g}}{\Delta \rho}\right]^{0.5}=0.548\left[\frac{h_{b}}{D_{C L}}\right]^{1.597},
$$

where $F r_{g}=\frac{W_{g}}{\rho_{g} A_{C L} \sqrt{g \cdot D_{C L}}}, \rho_{g}, \Delta \rho, D_{C L}, A_{C L}, g$, and $W_{g}$ are gas Froude number, gas density, density difference, cold leg diameter, cold leg area, gravity constant, and steam mass flow rate, respectively. Considering the steam flow rate from the intact cold legs and the system parameters such as the pressure and temperature, the critical void height is calculated to be about $0.1 \mathrm{~m}$ during LB-CL- 11 . The critical void height from Cho's correlation is based on the collapsed level. The critical void height in Equation (6) was developed under the single-phase condition. When the down-comer is in a mixture condition, as shown in Fig. 2, the mixture level could be used to calculate the critical void height. Although the mixture level could not be measured with the level transmitter, the mixture level is estimated to be much higher than the collapsed water level during the present test, and, thus, the sweep-out could occur with a lower collapsed level than that calculated from Equation (6).

Figure 8 shows the accumulated masses measured with the CS and estimated from the RCS inventory change together with the break flow rate during the reflood test. There was some difference between their accumulated masses in the initial stage of the test, but they were matched well in an overall sense. Their final mass difference was $20.2 \mathrm{~kg}$, and its error was about $2.5 \%$ of the final mass. It could be concluded that the total accumulated mass was measured reasonably well by using the CS, and this measurement could be complemented by the estimate from the RCS inventory change during the earlier stage before 1,680 s. As shown in Fig. 8, the break flow rate is high and fluctuating during the earlier stage, which is estimated from the RCS inventory change with relatively larger uncertainty, and it maintains a low steadier flow thereafter, which is measured by using the CS with relatively lower uncertainty. Their total errors were estimated to be 0.07 and $0.59 \mathrm{~kg}$ for the CS and RCS methods, respectively. The break flow rates were estimated by the RCS (Reactor Coolant System) inventory change before $1,680 \mathrm{~s}$, and they were calculated based on break flow rates measured by CS (Containment Simulator) after 1,680 s. They were different before 1,680 s, and they showed similar trends
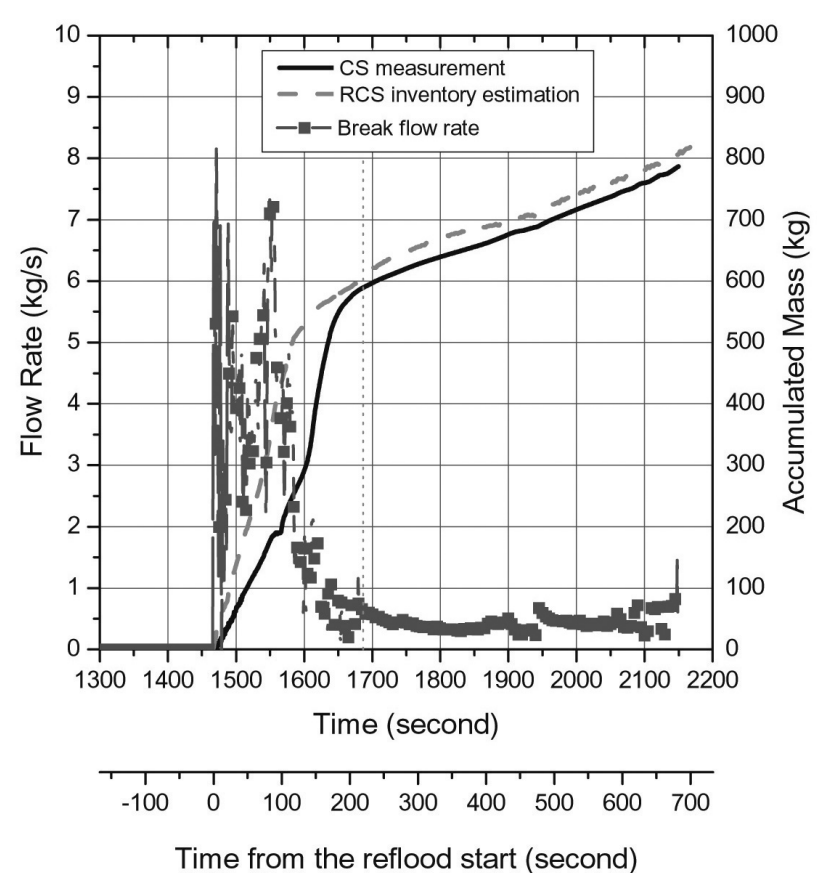

Fig. 8. Accumulated Masses and Break Flow Rate 
to each other thereafter.

Figure 9 presents the measured ECC flow rate variations during the reflood test. It is shown that the required flow rates are provided by four SITs and an SIP. The specified SIT flow rate of the APR1400 was simulated by installing orifices in the SIT injection line and by changing the opening of the flow control valve, for the high and low flow conditions, respectively, and the specified safety injection flow rate of the APR 1400 was simulated by the rotational speed of the metering-type SIP in ATLAS. The flow rates were a little different from each other due to the different system characteristics for the injection lines.

Figure 10 shows the ECC bypass fraction during LBCL-11. The ECC bypass fractions were calculated from Equation (5) based on the break flow rate and the injected SI flow rate, which were graphed in Figs. 8 and 9, respectively. As the break flow rates measured by CS could not provide reasonable results before $1,680 \mathrm{~s}$, those estimated by RCS were used even though the latter one had larger uncertainty than the former one. The variation of the ECC bypass fraction showed a rather complicated shape during the LB-CL-11 test. The ECC bypass fractions fluctuated frequently between 0.2 and 2.1 during the initial period, which surely shows that the sweep-out occurs significantly during the period. They are between 0.2 and 0.6 during the later period except for some irregular peaks. As discussed in Section 4.2, concerning the down-comer boiling phenomena, the ECC bypass fraction was very high during short periods around 1,550 s due to the sweepout and increased direct ECC bypass. During the period,

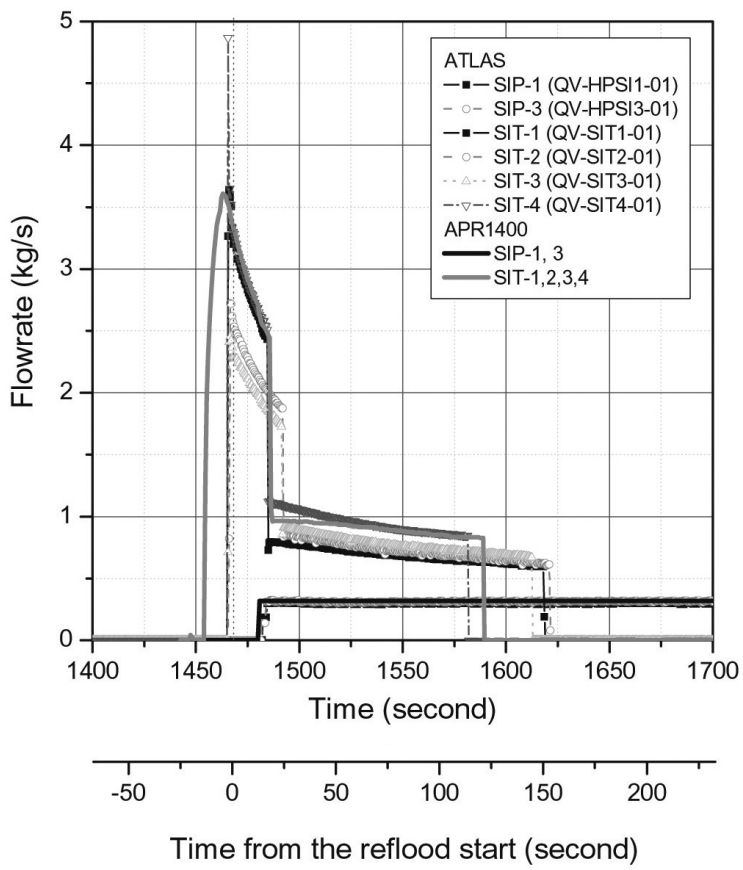

Fig. 9. Comparison of Measured ATLAS ECC Flow Rates and APR1400 Design Values the bypass fraction fluctuated very much and it maintained a high value. After 1,680 s the bypass fraction maintained a relatively steady value. As the break flow rate varied around 1,900 s, the ECC bypass fraction also fluctuated in accordance with that time scale in the LB-CL-11 test.

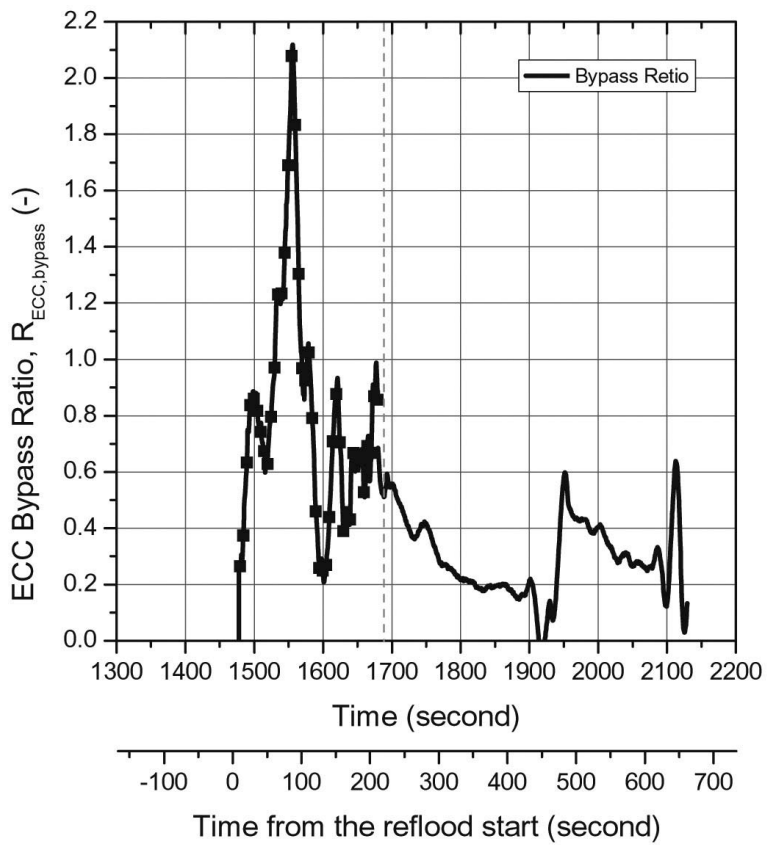

Fig. 10. ECC Bypass Fraction During the Reflood Phase

\subsection{Steam Binding}

Figure 11 shows a schematic diagram of the steam binding phenomenon in the ATLAS primary system during the LBLOCA reflood tests. Although steam discharge takes place through the break point of the RPV side, the steam binding phenomena was mainly due to the pressure loss and head increase along the flow path of steam from the upper plenum to break point of the RCP (Reactor Coolant Pump) side. The steam binding phenomena is a thermal-hydraulic process that could limit the flow of coolant into the core. Some of the coolant leaves the core as liquid or entrained droplets, enters the upper plenum, passes through the hot legs, and moves into the steam generator U-tubes. When the primary system pressure has decreased below that of the steam generator secondary side early in the accident, a reverse heat transfer begins to be activated from the steam generator secondary side to the primary side by the coolant flowing into the steam generator U-tubes. The increased resistance to the flow of steam to the break location increases the upper plenum pressure. This phenomenon is known as 'steam binding'. The increased pressure at the top of the core relative to the broken-loop cold legs rapidly causes the water in the core to be pushed backward through the core into the lower plenum and then into the down-comer. 
The steam binding is the phenomenon that poses back pressure at the core exit to decrease the rewetting velocity. The relative increase of the pressure at the core exit is caused by both the water head due to coolant accumulation in the upper plenum and the SG inlet plenum, and the pressure loss due to an increase in the velocity of steam flow towards the break through SG U-tubes, loop seal, and RCP in the broken loop. Furthermore, the steam superheating in SG U-tubes may contribute to the velocity acceleration of the steam flow.

The thermal-hydraulic parameters of fluid temperature, flow rate, and loop water level were analyzed to verify the fluid characteristics in the RCS loop and the reflux condensation heat transfer from the steam generator. Figure 12 shows the typical fluid temperatures in the primary system. As the steam moved from the core outlet through hot leg \#1, SG \#1 U-tubes, and cold leg \#1A to the down-comer, the steam became superheated between SG U-tubes and the cold leg due to the reverse heat transfer from SG. Figure 13 shows the behavior of the pressure difference between the upper head and break location, and the level difference between the down-comer and core. The level difference also increases except for the initial $280 \mathrm{~s}$ until $1,750 \mathrm{~s}$ from the test start. After the reflood start, the level decrease is caused by the saturation of the water inventory in the lower down-comer and in the lower plenum. The differential pressure increases according to the variation of the level difference throughout the test.

During the LB-CL-11 test, the steam binding effect is considered to be significant from the reflood start until $1,580 \mathrm{~s}$, around which the pressure difference drops drastically, as shown in Fig. 13. During that period, the core exit pressure kept high due to the increased pressure

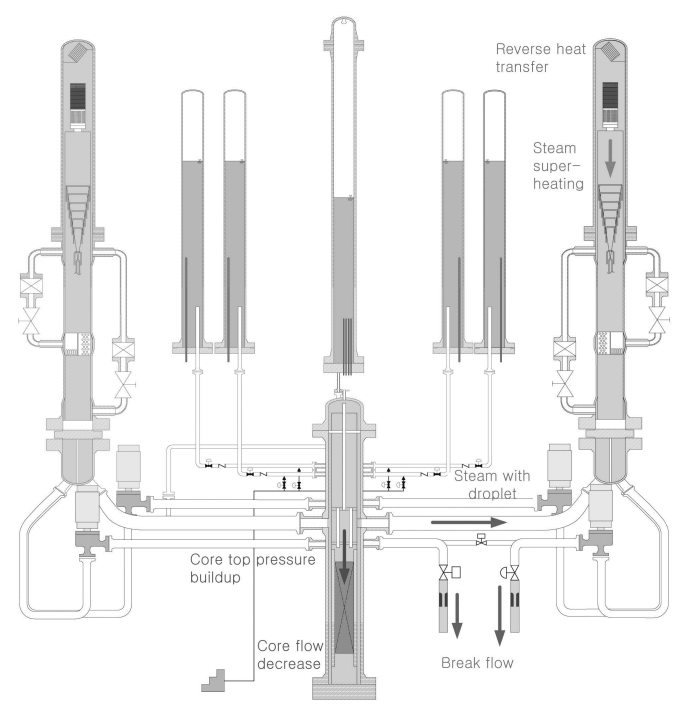

Fig. 11. Schematic Diagram of the Steam Binding Phenomenon in ATLAS loss throughout the flow path from the core exit to the break point and the accumulated water at the core exit. As shown in Fig. 13, the pressure at the upper head, which is close to the pressure at the core exit, remained high during the period, and also, as shown in the subsectional liquid level of LT-CO-07 in Fig. 2, the water

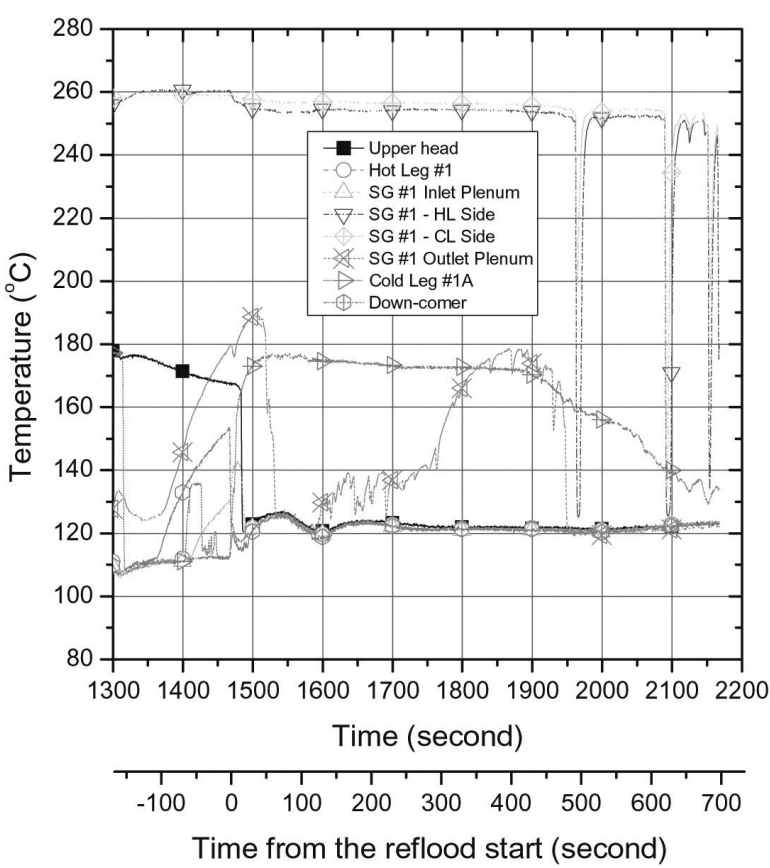

Fig. 12. Behavior of the Fluid Temperatures in the Primary System

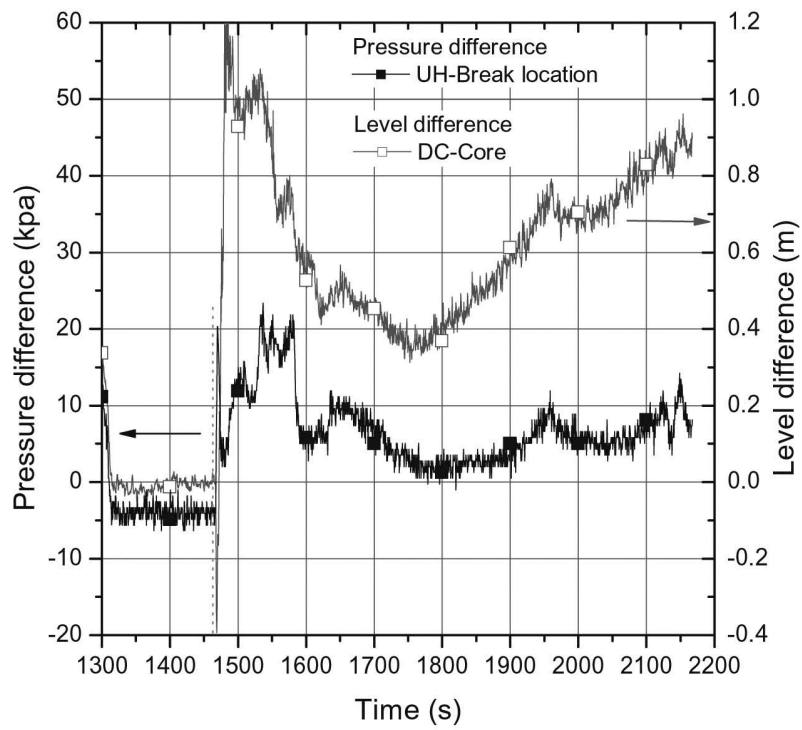

Fig. 13. Behavior of the Pressure Difference of the Upper Head and the Break Location and Level Difference of the Down-comer and Core 
was accumulated at the core exit. After $1,580 \mathrm{~s}$, the pressure difference decreased, as shown in Fig. 13, but still a lot of water was accumulated at the core exit (LT-CO-07) and in the upper plenum (LT-UP-01) to increase the pressure at the core exit when its pressure was compared with that in the down-comer. The increased pressure at the core exit deterred the ECC flow into the core and the collapsed water levels in the down-comer region also increased, which was shown in Fig. 2.

Some typical characteristics showing the steam binding phenomena were found during the LB-CL-11 test, and the changes of the down-comer and core levels could be explained based on the steam binding phenomena. However, the effect of steam binding on the core cooling behavior is rather indirect, but the water levels of the core and down-comer affect the core cooling behavior directly. In order to identify whether the steam binding effect exists or not, the core reflood rate for the case that droplet flow exists at the inlet of SG U-tube must be compared with that without droplet flow. It could be done in future research by using the best-estimate system code.

\section{CONCLUSIONS}

The ATLAS facility could provide unique data peculiar to APR1400. Four important thermal-hydraulic phenomena of core quenching, down-comer boiling, steam binding, and ECC bypass were identified during an LBLOCA reflood test by using ATLAS. Major findings are as follows.

1. Both bottom quenching and top quenching were observed for a uniform radial power profile during the LB-CL-11 test. Bottom quenching and top quenching occurred in homogeneous and inhomogenous manners, respectively. The top quenching phenomena occurred more quickly in the center and middle regions than in the outer region in a radial direction due to the effects of accumulated water inventory in the upper plenum and core top during the LB-CL-11 test.

2. It was shown from the scaling analysis that the present reflood test was performed in a condition in which the scaled heat flux from the RPV wall of ATLAS was higher than that for APR1400 even though the initial value was matched during the LB-CL-11 test. The down-comer boiling phenomenon was observed in the lower part of the down-comer, but its void fraction was smaller when compared with the RELAP5 simulation results.

3. The direct ECC bypass was the dominant ECC bypass mechanism throughout the test even though sweepout occurred during the earlier period. The ECC bypass fractions fluctuated very much due to the increased direct ECC bypass and the significant sweep-out during the initial period. It was between 0.2 and 0.6 only by the direct ECC bypass during the later period of the LB-CL-11 test.
4. Some typical characteristics showing the steam binding phenomena were found during the LB-CL-11 test and the changes of the down-comer and core levels could be explained based on the steam binding phenomena.

As future work, the ATLAS reflood tests could be analyzed by using best-estimate system analysis codes such as MARS, RELAP5, and TRACE to assess their reflood models and the assessed or revised codes could be used to help validate the LBLOCA licensing methodology.

\section{ACKNOWLEDGEMENTS}

This study had been carried out under the nuclear R\&D program by the Korean Ministry of Education, Science and Technology (MEST) of the South Korean government under the national nuclear mid- \& long-term R\&D programs.

$\begin{array}{ll}\text { NOMENCLATURE } \\ A, \text { a } & \text { area }\left[\mathrm{m}^{2}\right] \\ D & \text { diameter }[\mathrm{m}] \\ F r_{g} & \text { gas Froude number }[-] \\ g & \text { gravitational acceleration }\left[\mathrm{m} / \mathrm{s}^{2}\right] \\ h & \text { heat transfer coefficient }\left[\mathrm{W} / \mathrm{m}^{2}-\mathrm{K}\right] \\ h_{b} & \text { critical void height }[\mathrm{m}] \\ k & \text { thermal conductivity }[\mathrm{W} / \mathrm{m}-\mathrm{K}] \\ l & \text { length }[\mathrm{m}] \\ Q & \text { heat transfer rate }[\mathrm{W}] \\ q^{\prime \prime} & \text { heat flux [W/m }] \\ R & \text { bypass ratio }[-] \\ T & \text { temperature }[\mathrm{K}] \\ W & \text { flow rate }[\mathrm{kg} / \mathrm{s}] \\ x & \text { thickness }[\mathrm{m}] \\ & \\ G \text { reeks } & \\ \Delta \rho & \text { density difference }\left[\mathrm{kg} / \mathrm{m}^{3}\right] \\ \rho_{\mathrm{g}} & \text { vapor density }\left[\mathrm{kg} / \mathrm{m}^{3}\right]\end{array}$

\section{Superscripts}

m exponent

\begin{tabular}{ll}
\multicolumn{2}{l}{ Subscripts } \\
b & bulk \\
$\mathrm{f}$ & liquid \\
$\mathrm{g}$ & vapor \\
$\mathrm{i}$ & inner \\
$\mathrm{m}$ & model \\
$\mathrm{o}$ & outer \\
$\mathrm{p}$ & prototype \\
$\mathrm{R}$ & ratio \\
$\mathrm{w}$ & wall \\
0 & reference
\end{tabular}

Abbreviations

ATLAS Advanced Thermal-Hydraulic Test Loop for Accident Simulation 


$\begin{array}{ll}\text { BE } & \text { Best-Estimate } \\ \text { BS } & \text { Break Simulator } \\ \text { CCFL } & \text { Counter-Current Flow Limitation } \\ \text { CL } & \text { Cold Leg } \\ \text { CLI } & \text { Cold Leg Injection } \\ \text { CS } & \text { Containment Simulator } \\ \text { DVI } & \text { Direct Vessel Injection } \\ \text { ECC } & \text { Emergence Core Cooling } \\ \text { EM } & \text { Evaluation Model } \\ \text { FLB } & \text { Feed-water Line Break } \\ \text { HTC } & \text { Heat Transfer Coefficient } \\ \text { IRWST } & \text { In-containment Refueling Water Storage } \\ & \text { Tank } \\ \text { KAERI } & \text { Korea Atomic Energy Research Institute } \\ \text { LBLOCA } & \text { Large Break Loss of Coolant Accident } \\ \text { MSLB } & \text { Main Steam Line Break } \\ \text { NRC } & \text { Nuclear Regulatory Commission } \\ \text { RCP } & \text { Reactor Coolant Pump } \\ \text { RCS } & \text { Reactor Coolant System } \\ \text { RPV } & \text { Reactor Pressure Vessel } \\ \text { RWT } & \text { Refueling Water Tank } \\ \text { SBLOCA } & \text { Small Break Loss of Coolant Accident } \\ \text { SGTR } & \text { Steam Generator Tube Rupture } \\ \text { SIP } & \text { Safety Injection Pump } \\ \text { SST } & \text { Steam Supply Tank }\end{array}$

\section{REFERENCES}

[1] S. J. Cho, et al.: The Development of Passive Design Features for the Korean Next Generation Reactor, Nuclear Engineering and Design, 201, 259 (2000).

[2] W. P. Baek, et al.: KAERI Integral Effect Test Program and the ATLAS Design, Nuclear Technology, 152, 183 (2005).

[3] W.P. Baek, et al.: LBLOCA and DVI Line Break Tests with the ATLAS Integral Facility, Nuclear Engineering and Technology, 41(6), 775-784 (2009).

[4] H. S. Park, et al.: An Integral Effect Test on the Reflood Period of a Large-Break LOCA for the APR1400 Using ATLAS, Nuclear Technology, 70, 100-113 (2010).

[5] M. Ishii and I. Kataoka: Similarity Analysis and Scaling Criteria for LWRs under Single Phase and Two-Phase Natural Circulation, NUREG/CR-3267, ANL-83-32, Argonne National Laboratory, USA (1983).

[6] H. S. Park, et al.: Calculation Sheet for the Basic Design of the ATLAS Fluid System, KAERI/TR-3333/2007, KAERI, Daejeon, Korea (2007).

[ 7 ] Y.S. Kim, et al.: Commissioning of the ATLAS Thermalhydraulic Integral Test Facility, Nuclear Technology, 35, 1791-1799 (2008).

[ 8 ] S. Cho, et al:: Description of the data acquisition-control system and instrumentation of the ATLAS test facility, Proceedings of WORTH-3 (The 3rd Sino-Korea Workshop In Nuclear Reactor Thermal Hydraulics), Aug. 22-24, Chengdu, China (2007).

[9] H.S. Park, D.J. Euh, K.Y. Choi, et al., "Pre-Test Analysis of a Large-Break LOCA for the ATLAS Facility," Proceedings of the NURETH-11, Avignon, France, October
2-6 (2005).

[10] K.Y. Choi, et al.: Experimental Simulation of a Direct Vessel Injection Line Break of the APR1400 with the ATLAS, Nuclear Engineering and Technology, 41(5), 655-676 (2009).

[11] U.S. NRC: Compendium of ECCS Research for Realistic LOCA Analysis, NUREG-1230-R4, U.S. NRC, Washington, DC, USA (1988).

[12] S. Cho, et al.: Core Thermal Hydraulic Behavior during the Reflood Phase of Cold-Leg LBLOCA Experiments using the ATLAS Test Facility, Nuclear Engineering and Technology, 41(10), 1263-1274 (2009).

[13] H. S. Park, et al.: An Integral Effect Test on the LBLOCA Reflood Phenomena for APR 1400 Using ATLAS in a Best-Estimate Condition, Journal of Nuclear Science and Technology, 46(11), 1059-1069 (2009).

[14] B. J. Yun, et al., "Investigation of the Downcomer Boiling Phenomena during the Reflood Phase of a Postulated Large-Break LOCA in the APR1400," Nuclear Technology 156, pp.56-68 (2006).

[15] H.C. Silva, et al., "Effect of downcomer boiling on LOCA PCT for a 4-loop PWR with a large-dry containment," The 10th Int. Topical Meeting on Nuclear Reactor Thermal Hydraulics (NURETH-10), Seoul, Korea, October 5-9 (2003).

[16] S.W. Lee and S.J. Oh, "Experimental Benchmarking and Safety Analyses of APR1400 Large Break LOCA Scenario," Proc. 5th Int. Congress on Advances in Nuclear Power Plants (ICAPP'05), Seoul, Korea, May 15-19 (2005).

[17] B. J. Yun, et al.: Downcomer Boiling Phenomena during the Reflood Phase of a Large-Break LOCA for the APR1400, Nuclear Engineering and Design, 238, 2064 (2008).

[18] H.S. Park, et al., "Recent ATLAS Test Results on the Late Reflood Period of the Large-Break LOCA for APR1400," IAEA Topical Meeting on Advanced Safety Assessment Methods for Nuclear Reactors, Daejeon, Korea, October 30-November 1 (2007).

[19] K.Y. Choi, et al.: Experimental Investigation on Downcomer Boiling with the ATLAS Facility, Proceedings of WORTH4 (The 4th Korea-China Workshop on Nuclear Reactor Thermal Hydraulics), May 18-20, Jeju, Korea (2009).

[20] K. Stephan and M. Abdelsalam, "Heat Transfer Correlations for Natural Convection Boiling," International Journal of Heat and Mass Transfer 23, pp.73-87 (1980).

[21] B. J. Yun, et al., "Scaling for the ECC bypass phenomena during the LBLOCA reflood phase," Nuclear Engineering and Design 231, pp.315-325 (2004).

[22] MPR-1324, "Summary of results from the UPTF downcomer injection/vent valve separate effects tests: Comparison to previous scaled tests, and application to Babcock \& Wilcox pressurized water reactors," (1992).

[23] K. H. Kang, et al., Characteristics of Direct ECC Bypass Phenomena on the Accident Simulation of Late-Phase Reflood in the APR1400, Proceedings of the $17^{\text {th }}$ International Conference on Nuclear Engineering (ICONE17), July 1216, Brussels, Belgium (2009).

[24] H. K. Cho, et al., "Scaling analysis for the Multi-dimensional Phenomena of the ECC Bypass during an LBLOCA with the Direct Vessel Injection," PhD. Thesis, Seoul National University (2004). 